\title{
SU-8 process optimization for high fiber coupling efficiency of liquid crystal filled photonic bandgap fiber components
}

Wei, Lei; Alkeskjold, Thomas Tanggaard; Bjarklev, Anders Overgaard

Published in:

Proceedings, OECC

Link to article, DOI:

10.1109/OECC.2009.5213148

Publication date:

2009

Document Version

Publisher's PDF, also known as Version of record

Link back to DTU Orbit

Citation (APA):

Wei, L., Alkeskjold, T. T., \& Bjarklev, A. O. (2009). SU-8 process optimization for high fiber coupling efficiency of liquid crystal filled photonic bandgap fiber components. In Proceedings, OECC (pp. 1-2). IEEE.

https://doi.org/10.1109/OECC.2009.5213148

\section{General rights}

Copyright and moral rights for the publications made accessible in the public portal are retained by the authors and/or other copyright owners and it is a condition of accessing publications that users recognise and abide by the legal requirements associated with these rights.

- Users may download and print one copy of any publication from the public portal for the purpose of private study or research.

- You may not further distribute the material or use it for any profit-making activity or commercial gain

- You may freely distribute the URL identifying the publication in the public portal 


\title{
SU-8 Process Optimization for High Fiber Coupling Efficiency of Liquid Crystal Filled Photonic Bandgap Fiber Components
}

\author{
L. Wei ${ }^{1}$, T. T. Alkeskjold ${ }^{2}$ and A. Bjarklev ${ }^{1}$ \\ ${ }^{1}$ DTU Fotonik, Department of Photonics Engineering, Technical University of Denmark, DK-2800 Lyngby, Denmark \\ Phone: +(45)45256370, Fax: +(45)45936581, Email: lewe@fotonik.dtu.dk \\ ${ }^{2}$ Crystal Fibre A/S, Blokken 84, DK-3460 Birkerød, Denmark
}

\begin{abstract}
SU-8 structures are built up to increase the fiber coupling efficiency of liquid crystal photonic bandgap fiber components. The resolution reduction of UV exposure is minimized to $4 \%$, and insertion loss is reduced to $2.7 \mathrm{~dB}$.
\end{abstract}

\section{Introduction}

Infiltrating Liquid Crystals (LCs) into the capillaries of a Photonic Crystal Fiber (PCF) changes the fibers guiding principle from modified Total Internal Reflection (mTIR) to bandgap guiding. Due to the physical properties of the LC, the optical characteristics of the Liquid Crystal infiltrated Photonic BandGap (LCPBG) fiber and its transmission spectrum can be tuned thermally, optically and electrically [1-10]. A compact polarimeter working at the $1550 \mathrm{~nm}$ region has also been developed [8]. However, the insertion loss of this device is $10.5 \mathrm{~dB}$ due to the misalignment of the Single Mode Fibers (SMFs) and PCF during the assembly.

Here, we experimentally improve the performance of this device by building up SU-8 fiber fixing structures on v-groove to maintain a good fiber coupling quality in device assembly. The SU-8 process is also optimized to minimize the resolution loss in UV exposure. Only $2.7 \mathrm{~dB}$ insertion loss for the whole device is obtained

\section{Device and experiments}

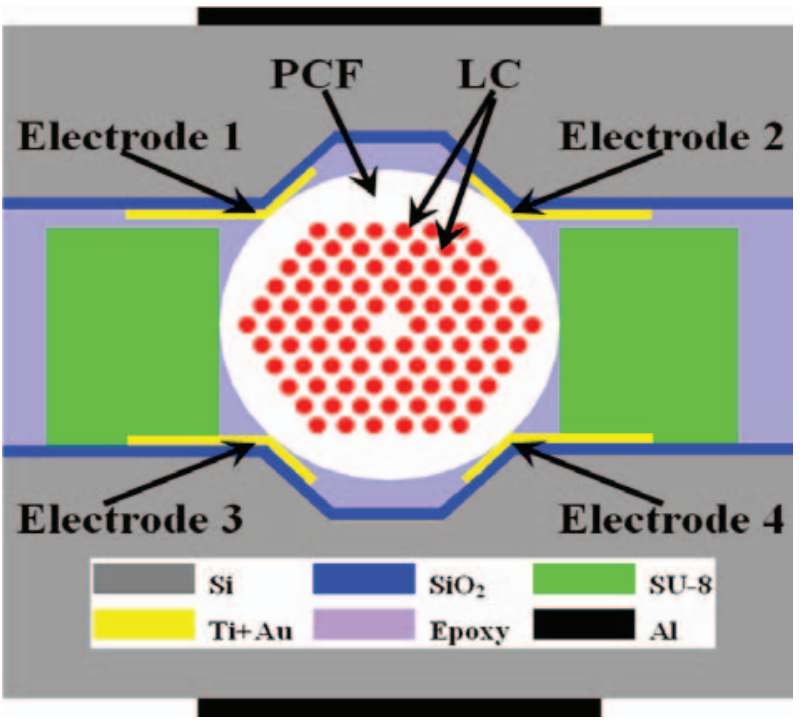

Fig. 1. The cross section of the LCPBG fiber device.
The cross section of the LCPBG device is illustrated in Fig. 1. The LC is infiltrated for $10 \mathrm{~mm}$ of the length of the fiber by using capillary forces, and then mounted between two v-grooves fabricated on a silicon substrate. Two SMF pigtails are also fixed in the grooves at each end of the LCPBG fiber for coupling in and out of the device. The Au electrodes are deposited on the side walls of the grooves, forming two orthogonal sets of electrodes. The electrode patterning is achieved by using thick photoresist coating and two-step exposure [11]. The assembly is sealed with epoxy, and the top and bottom sides of the device are electrically grounded.

In order to ensure a high fiber coupling quality, SU8 fiber fixing structures are built up on the electrodes. The height of each structure is $80 \mu \mathrm{m}$, since the space between top and bottom chips is $\mathrm{D} / 1.414=88.4 \mu \mathrm{m}$, where $\mathrm{D}$ is the outer diameter of the fiber $(\mathrm{D}=125 \mu \mathrm{m})$. The distance between two neighboring structures is $126 \mu \mathrm{m}$, taking the small variation of the fiber outer diameter into account. The profile of the edge bead resulting from the standard SU-8 process is shown in Fig. 2(a). The edge bead protrudes more than $30 \mu \mathrm{m}$ above the $80 \mu \mathrm{m}$ thick SU-8 film. This air gap between the mask and the resist reduces the theoretical resolution of UV exposure by $36 \%$ [12].

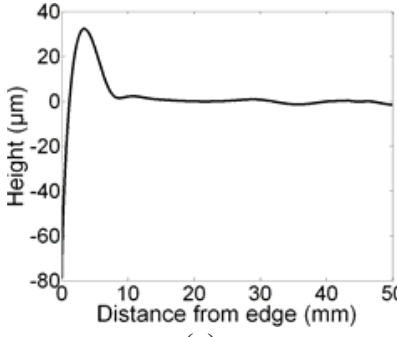

(a)

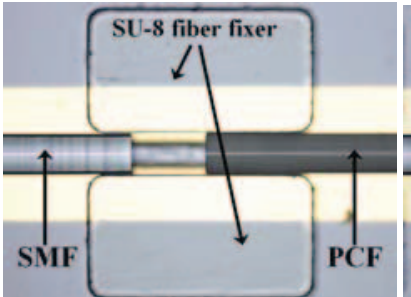

(c)

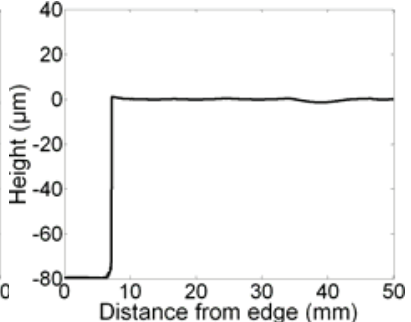

(b)

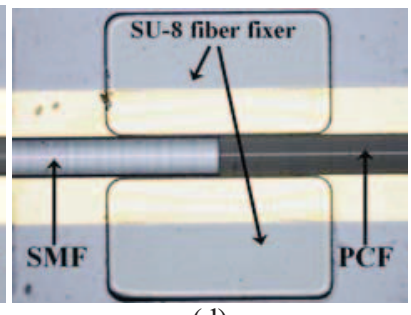

(d)
Fig. 2. The profile scans of $80 \mu \mathrm{m}$ thick SU-8 film (a) before EBR and (b) after EBR. The quality of fiber coupling between SMF and PCF is improved by using SU-8 fiber fixers (c) before coupling and (d) after coupling. 
Minimizing the height of the edge bead is performed in three steps [13]: a solvent reduction bake, the actual edge bead removal (EBR), and a post-EBR spin cycle. The actual EBR is performed using the EBR functionality of the spin coater. While the wafer spins at $500 \mathrm{rpm}$, propylene glycol monomethyl ether acetate (PGMEA) is applied at the edge of the wafer through a needle. The secondary edge bead from the reflowed SU8 is minimized by a spin cycle immediately after the EBR. Figure 2(b) shows the profile of SU-8 film after EBR. Only $3 \mu \mathrm{m}$ protuberance is observed, and the reduction of the theoretical resolution is minimized to $4 \%$. Figure 2(c) and (d) show the coupling between SMF and PCF on the v-groove by using SU-8 fiber fixers. It is obvious to see that the coupling is improved and succeedingly protected by SU-8 structures in the device assembly, which minimizes the misalignment in [8] and subsequently reduces the total insertion loss of the device.

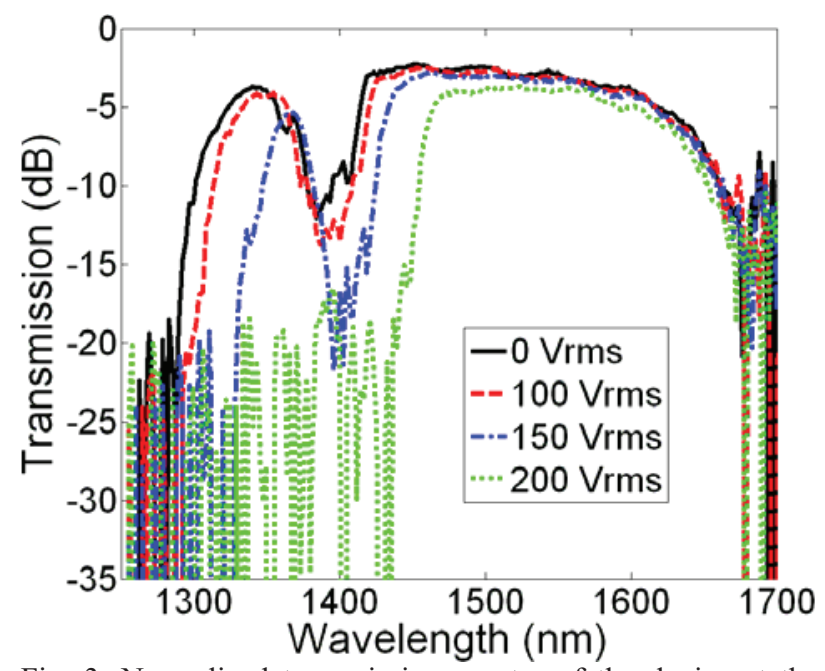

Fig. 3. Normalized transmission spectra of the device at the driving voltage of $0 \mathrm{Vrms}, 100 \mathrm{Vrms}, 150 \mathrm{Vrms}$ and $200 \mathrm{Vrms}$.

The performance of this device is tested using a broadband light from a supercontinuum source (SuperK, Koheras A/S, Denmark). The transmission spectrum is measured by an optical spectrum analyzer $(0.5 \mathrm{~nm}$ resolution), and normalized to the spectrum without inserting the device. The fiber used in the experiments is a Large Mode Area PCF (LMA-13, Crystal Fibre A/S, Denmark), with a solid core surrounded by 5 rings of air holes arranged in a triangular lattice. The hole diameter, inter-hole distance and outer fiber diameter are $4.3 \mu \mathrm{m}$, $8.5 \mu \mathrm{m}$ and $125 \mu \mathrm{m}$, respectively. The liquid crystal is MDA-00-3969 (Merck, Germany), which has a wavelength dependent ordinary and extraordinary refractive index of $n_{0}=1.4978$ and $n_{e}=1.7192$ at $589.3 \mathrm{~nm}$. The electrical permittivity at $1 \mathrm{kHz}$ is $\varepsilon \perp=7.3 \varepsilon_{0}$ along the ordinary axis and $\varepsilon_{/ /}=10.6 \varepsilon_{0}$ along the extraordinary axis. All values are at $20^{\circ} \mathrm{C}$. Polarized microscopy observations on a single LC infiltrated $5 \mu \mathrm{m}$ diameter capillary showed that the LC used in this experiment aligned in a $45^{\circ}$ splayed alignment [4].
The device is driven in bipolar mode by using two driving signals $\mathrm{Vs},-\mathrm{Vs}$. The $1 \mathrm{kHz}$ sine wave driving voltage $\mathrm{Vs}$ for the device is generated by a signal generator and the phase-shifted signal $-\mathrm{Vs}$ is generated by an inverter. Vs and $-\mathrm{Vs}$ are amplified using highvoltage amplifiers and the DC components of Vs and - Vs are removed by two $80 \mathrm{~Hz}$ high-pass filters.

Figure 3 shows the transmission spectrum with applied voltage from $0 \mathrm{~V}_{\text {rms }}$ to $200 \mathrm{~V}_{\text {rms }}$ at room temperature. The notch in the transmission spectrum is caused by a cladding mode crossing through the bandgap starting at $1300 \mathrm{~nm}$, forming a so-called "avoidedcrossing" with the core mode of the bandgap. This notch splits the whole bandgap into two parts. The same phenomenon has also been found by infiltrating PCFs with $90^{\circ}$ splayed aligned LC MLC-6608 [9]. It is evident that the short-wavelength edge is shifted towards longer wavelengths by increasing the voltage, while the longwavelength edge of the same bandgap centered at $1500 \mathrm{~nm}$ is almost kept in the original position. This feature is caused by different sensitivity of the PBG modes to the electrically induced alignment of LC [10]. At $200 \mathrm{Vrms}$, an activation loss of $1.3 \mathrm{~dB}$ is observed at $1500 \mathrm{~nm}$

\section{Conclusions}

In conclusion, we experimentally minimize the resolution loss of the standard SU-8 process in UV exposure by removing the edge bead, and improve the fiber coupling quality by using SU-8 fiber fixing structures on LCPBG fiber device. The total insertion loss of this all-in-fiber device is $2.7 \mathrm{~dB}$. The electrical tunability of this compact device is also tested. With different driving voltages, an unbalanced shift of bandgap edge is found, which is caused by different sensitivity of the PBG modes to the electrically induced alignment of LC. The stable and compact design enables this all-in-fiber device easily integrated into communication or sensor systems.

\section{References}

1. T. T. Larsen et al, Opt. Express 11(2003), p.2589-2596

2. T. T. Alkeskjold et al, Opt. Express 12 (2004), p.5857-5871

3. M. W. Haakestad et al, IEEE Photon. Technol. Lett. 17 (2005), p.819-821

4. L. Scolari et al, Opt. Express 13(2005), p.7483-7496

5. D. C. Zografopoulos et al, J. Lightwave Tech. 24(2006), p.3427-3432

6. T. R. Wolinski et al, Opto-Electron. Rev. 14(2006), p.329334

7. D. Noordegraaf et al, Opt. Express 15(2007), p.7901-7912

8. T. T. Alkeskjold et al, Opt. Lett. 32(2007), p.1707-1709

9. L. Wei et al, Appl. Opt. 48(2009), p.497-503

10. J. Weirich et al, Opt. Express 6(2009), p.4442-4453

11. L. Wei et al, Electron. Lett. accepted for publication

12. L. F. Thompson et al, Introduction to Microlithography (American Chemical Society, 1983)

13. M. Shaw et al, Microsyst. Technol. 10(2003), p.1-6 